\title{
RELATIONS OF EFFECTIVE RENAL BLOOD FLOW AND GLOMERULAR FILTRATION TO TUBULAR EXCRETORY MASS IN NORMAL MAN 1
}

\author{
By WILLIAM GOLDRING, HERBERT CHASIS, HILMERT A. RANGES, AND \\ HOMER W. SMITH \\ (From the Departments of Physiology and Medicine, New York University College of Medicine, \\ and the Third (New York University) Medical Division of \\ Bellerue Hospital, New York City)
}

(Received for publication May 13, 1940)

In 1938 Smith, Goldring and Chasis (12) described methods for measuring the "effective renal blood flow" (diodrast clearance) and the "tubular excretory mass" (diodrast $T m$ ) by the excretion of diodrast at low and high plasma levels. The present report concerns the application of these methods to normal subjects under standard or quasi-basal conditions, with special reference to the quantitative relations between the diodrast clearance, the inulin clearance and diodrast $T m$ in various subjects.

The subjects examined here were convalescent, volunteer patients of the Third (New York University) Medical Division of Bellevue Hospital, and were selected as carefully as possible to exclude renal disease. Clearance determinations were carried out in the morning without breakfast, although in a few instances a glass of orange juice was allowed. The subject was hydrated by the administration of one liter of water the night before; the water was measured out for him and he was allowed to take it ad libitum and without supervision. The next morning a second liter of water was taken between 7:00 and 8:30 a.m., and the subject was allowed out of bed momentarily. At about 9:00 a.m. an intravenous infusion containing the requisite concentrations of diodrast,

\footnotetext{
1 This investigation has been aided in part by a grant from the Commonwealth Fund.

The authors are indebted to the Winthrop Chemical Company for generously supplying some of the diodrast used in the later observations, and to Messrs. Hynson, Westcott and Dunning for the preparation of phenol red in sterile 10 per cent solution. They also wish to express their appreciation of the continued interest of the Pfanstiehl Chemical Company in the preparation of pure inulin. Recently, the U. S. Standard Products Company, Woodworth, Wisconsin, with the co-operation of $\mathrm{Dr}$. Alf S. Alving, have made physiologically tested inulin available in sterile ampules.
}

phenol red and inulin in 0.9 per cent saline was started, and urine collections were begun after a suitable washout period. Urine was collected by catheter, the bladder being rinsed with saline at the termination of each urine collection period. Sterile technique was observed throughout.

\section{DIODRAST CLEARANCE}

It has been our custom after 3 or 4 periods, during which the diodrast clearance has been measured at low plasma levels of diodrast ( 0.8 to $2.0 \mathrm{mgm}$. per cent of diodrast iodine), to proceed to some observation on the action of a physiologic or pharmacologic stimulus upon the renal circulation; or alternatively, to elevate the plasma level of diodrast to 15 to $50 \mathrm{mgm}$. per cent of diodrast iodine, in order to saturate the tubules and measure the "tubular excretory mass," i.e., the maximal rate of tubular excretion (diodrast $T m$ ). The initial clearance periods obtained on a particular day and uncomplicated by any factor other than those specified we have averaged into a single datum which we designate here as the diodrast clearance $C_{D}$. Thus the data on $C_{D}$ recorded here (Tables I and II) for a particular date represent the average of 3 or more consecutive clearance periods. We feel that 3 such consecutive periods are the least upon which a trustworthy average figure can be based. ${ }^{2}$

\section{DIODRAST $T m$}

For the measurement of diodrast $T m$ (Tables I, II and III), the plasma level of diodrast must

2 Chesley and Chesley (2) have misinterpreted our preliminary reports, in that they have suggested that we have included in our standard observations clearance periods when sodium sulphate was being administered. Sodium sulphate, or more recently mannitol, has been used to maintain the urine flow in special circumstances, but such data are not included here. 
be raised to a point where the tubules are excreting this substance at a maximal rate. (Under these conditions the diodrast clearance as ordinarily defined $(U V / P)$ has, of course, no direct physiological significance.) The rate of tubular excretion of diodrast, $T_{D}$, is calculated as the difference between the total quantity excreted per minute and the quantity excreted by filtration, i.e.,
(1)

$$
\begin{aligned}
T_{D} & =U_{D} V-P_{D} C_{I N} F W \\
& =\left(\frac{C_{D}}{C_{I N}}-F W\right) P_{D} C_{I N},
\end{aligned}
$$

where $U_{D}$ and $P_{D}$ are the concentrations of diodrast iodine in mgm. per cc. of urine and plasma, respectively; $V$, the urine flow in cc. per minute; $C_{I N}$ and $C_{D}$ the inulin and diodrast clearances in

TABLE I

Diodrast clearance, etc., in normal men

(Columns 5, 6, 7, 8 and 11 corrected to 1.73 sq. m.)

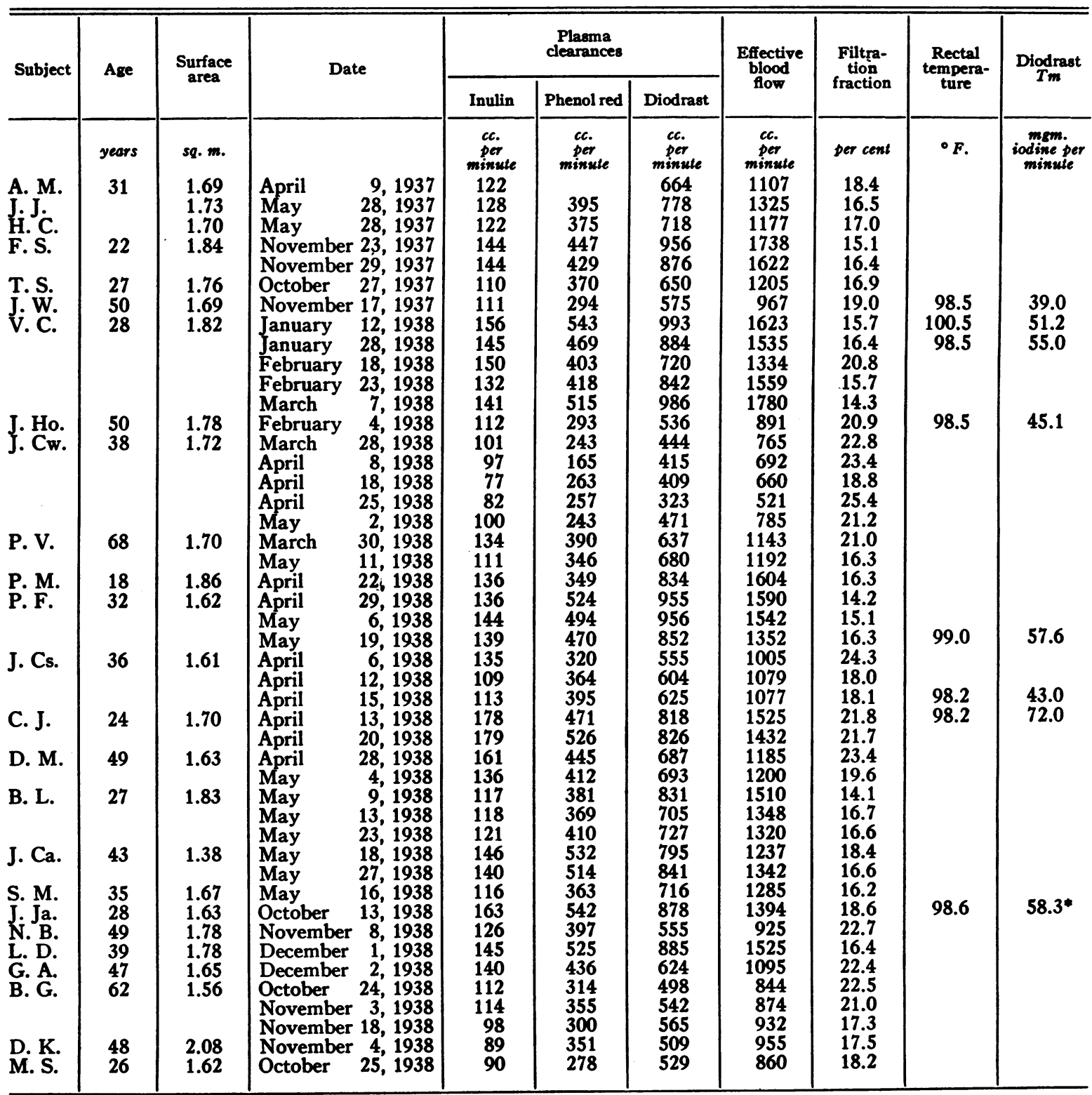


TABLE I-Continued

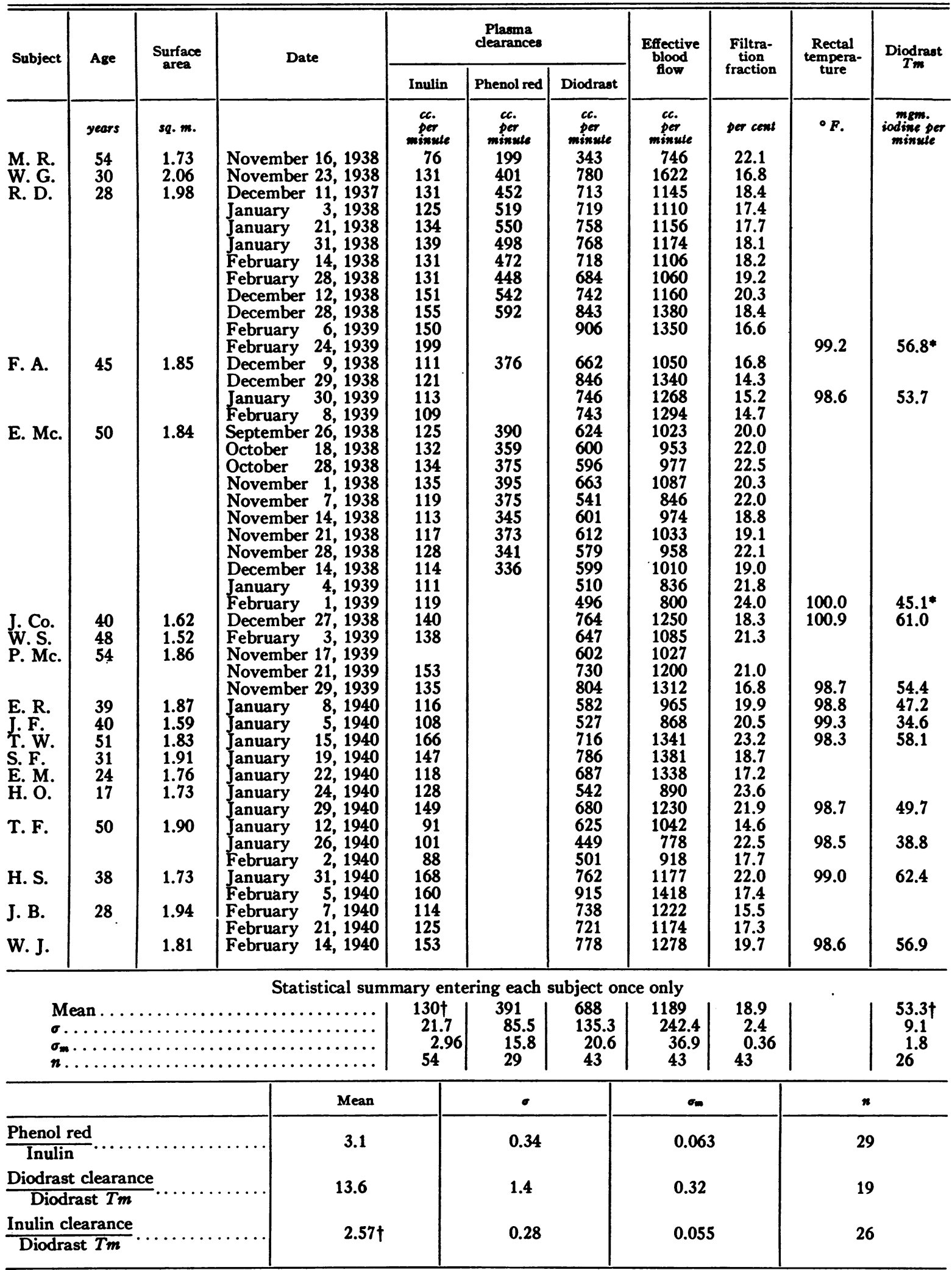

- Diodrast $T m$ is average of observations on this day with other observations in Table III.

t Includes subjects shown in Table III.

$\sigma_{m}=$ Standard Error of Mean $=\sigma / \sqrt{n}$. 
TABLE II

Diodrast clearance, etc., in normal women

(Columns 5, 6, 7 and 10 corrected to 1.73 sq.m.)

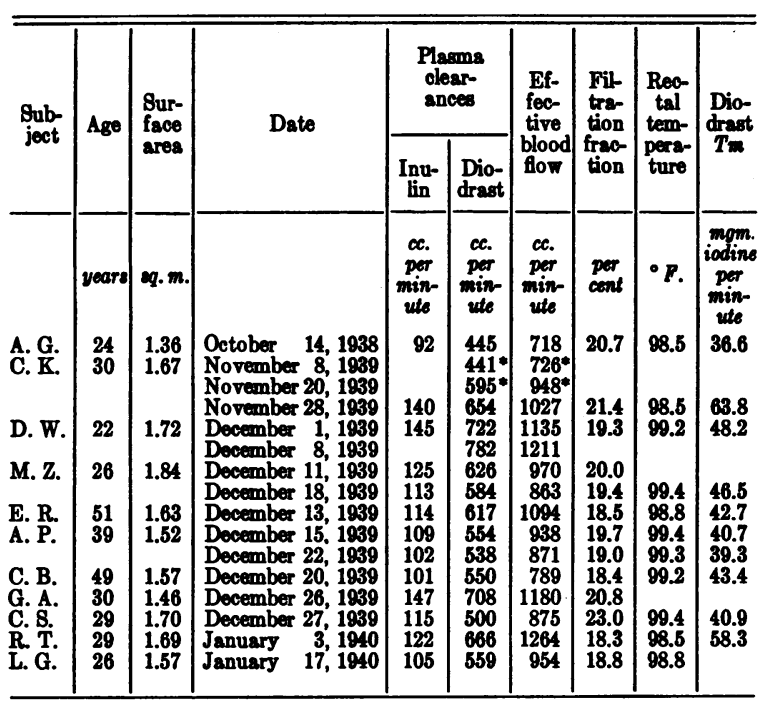

Statistical summary entering each subject once only

\begin{tabular}{|c|c|c|c|c|}
\hline 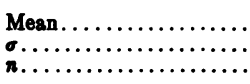 & \begin{tabular}{l|l}
$\ldots$ & 118.7 \\
$\ldots$ & 17.5 \\
$\ldots$ & 11
\end{tabular} & $\left|\begin{array}{c|c}600.4 & 996 \\
87.0 & 162.7 \\
11 & 11\end{array}\right|$ & $\left|\begin{array}{c}19.8 \\
1.4 \\
11\end{array}\right|$ & $\left|\begin{array}{c}46.7 \\
8.5 \\
9\end{array}\right|$ \\
\hline & Mean & $\sigma$ & & $n$ \\
\hline$\frac{\text { Diodrast clearance }}{\text { Diodrast } T m}$ & 12.8 & 1.52 & & 9 \\
\hline$\frac{\text { Inulin clearance }}{\text { Diodrast } T_{m}}$ & 2.54 & 0.28 & & 9 \\
\hline
\end{tabular}

* Omitted from average.

cc. of plasma per minute; $F$, the fraction of diodrast which is free and therefore filtrable, as determined by the plasma concentration of diodrast iodine and the plasma albumin content (see nomogram of Smith and Smith (13)) ; and $W$ is taken approximately as 1.00 -per cent of plasma protein/100.

Albumin and total protein determinations were made by us on 57 occasions on 31 subjects, and it was found that $F W$ averaged $0.72 \pm 0.025$. In a subject with diodrast $T m$ of 52 , inulin clearance of $125 \mathrm{cc}$. and a plasma level of diodrast iodine of $20 \mathrm{mgm}$. per cent, a deviation in $F W$ of \pm 0.02 makes only \pm 1.0 per cent error in diodrast $T m$. Wherever possible, however, protein determination should be made for diodrast $T m$ measurement in renal disease.

In the determination of diodrast $T m$, the total "load" of diodrast carried to the tubules must, of course, exceed the maximal rate of excretion if the tubules are to be saturated. The diodrast load/diodrast $T m$ ratio in our observations ranges from 1.5 to 5.0. Any ratio above 1.5 appears to be satisfactory for this measurement. ${ }^{3}$ We routinely take the average of 5 periods of ten to fifteen minutes each for this datum.

It early became clear that diodrast $T m$, involving as it does a "saturation" phenomenon, or maximal excretory activity on the part of the tubules, is very susceptible to changes in body temperature. Observations made upon the same subjects at different temperatures indicate a temperature coefficient of about 2.0 for the excretory process, i.e., a rise of $1.0^{\circ} \mathrm{F}$. in body temperature increases the $T m$ value by about 10 per cent. Consequently, in all measurements of diodrast

TABLE III

Data on glucose $T m$, etc., in normal men (Columns 6, 8 and 9 corrected to 1.73 sq.m.)

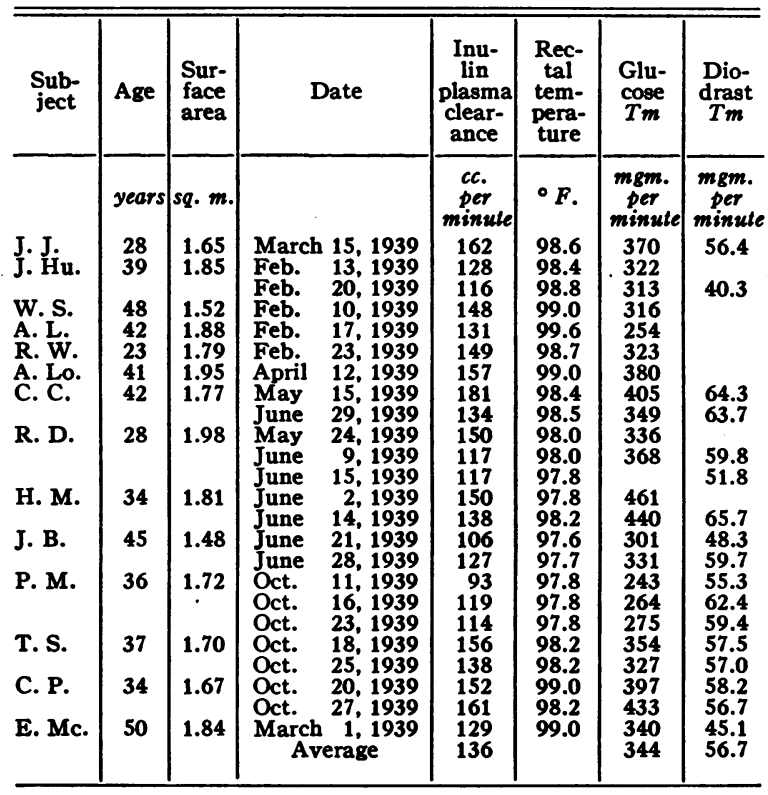

3 The load of diodrast carried to the tubules is the product of the plasma concentration and the renal plasma flow. It is assumed that the renal plasma flow remains the same during diodrast $T m$ measurement as in the control observations; hence we calculate the load as $P_{D}\left(C_{D}\right.$ $-F W C_{I N}$ ), i.e., the actual plasma concentration of diodrast during $T m$ measurement times the average diodrast clearance $\left(C_{D}\right)$ observed at low plasma diodrast levels, minus the quantity of diodrast filtered per minute. Filtered diodrast is deducted in this calculation inasmuch as after diodrast has been filtered through the glomeruli it is no longer available for either tubular excretion or for saturation of the tubules. 
$T m$ (as indeed in all our observations) the rectal temperature is recorded every twenty to thirty minutes. The rectal temperatures observed by us range from 97.5 to $99.5^{\circ} \mathrm{F}$. and average $98.5^{\circ}$ $F$., and we have corrected all figures for diodrast $T m$ reported here to $98.5^{\circ} \mathrm{F}$. by adding or subtracting 10 per cent to the observed value for each degree of body temperature above or below this value.

On a very few occasions we have observed transient urticaria during diodrast $T m$ measurement. No serious disturbances have been encountered, although we have on numerous occasions elevated the plasma level of diodrast to 50 $\mathrm{mgm}$. per cent of iodine or higher for periods of one hour or more.

\section{PHENOL RED CLEARANCE}

The phenol red clearance was followed until December, 1938, at which time it was abandoned in favor of other observations. Phenol red $T m$ has been reported in only one subject (12) and is not recommended."

\section{GLUCOSE $T m$}

Shannon and Fisher (9) have shown that, when the plasma concentration of glucose is elevated to a sufficient level, the rate of reabsorption of glucose by the renal tubules in the dog becomes maximal and constant. We here briefly report that we have found the same thing to be true in normal man, and include measurements of the maximal rate of tubular reabsorption of glucose, or glucose $T m$, in 14 subjects (Table III).

The rate of tubular reabsorption of glucose $\left(T_{G}\right)$ is calculated as the difference between the total quantity filtered per minute and the quantity excreted in the urine, i.e.,

$$
T_{G}=P_{G} C_{I N}-U_{G} V
$$

where $C_{I N}$ is the inulin clearance, $P_{G}$ and $U_{G}$ are the concentrations of glucose per cc. of plasma

\footnotetext{
4 Phenol red $T m$ measurement requires plasma concentrations of $25 \mathrm{mgm}$. per cent, at which level the skin discoloration is disturbing to the patient; moreover, phenol red, when given intravenously in large doses in dogs, frequently causes nausea and a marked fall in the filtration rate, and if used for this purpose in these or other animals should be given subcutaneously or intramuscularly.
}

and urine, respectively, and $V$ is the urine flow in cc. per minute. In order to raise $T_{G}$ to its maximal value (glucose $T m$ ) (i.e., to saturate all tubules whose glomeruli are maximally or nearly maximally active), the load of glucose delivered to the tubules should exceed the maximal rate of reabsorption by at least 20 per cent, i.e., the glucose load/glucose $T m$ ratio should exceed 1.20. The load of glucose carried to the tubules is the product of the plasma concentration and the rate of glomerular filtration in cc. of plasma, i.e., $P_{G} C_{I N}$. At high plasma levels of glucose, slight errors in the determination of plasma glucose or the inulin clearance introduce disproportionately large errors in the calculation of glucose $T m$, and maximal accuracy is attained at a load $/ T m$ ratio of 1.4 to 1.6. Glucose $T m$ should be determined with a rising or constant plasma glucose concentration, since the reabsorptive process exhibits an unexplained hysteresis (Shannon and Troast, personal communication).

The measurement of glucose $T m$ is valuable for two purposes: First, it affords a measure of the quantity of intact tubular reabsorptive tissue, or the "tubular reabsorptive mass" of the kidney, in contrast to the "tubular excretory mass" as measured by diodrast $T m$. Second, it affords a method of evaluating the number of "active" nephrons, and hence open glomeruli, since at an appropriate plasma level of glucose a critical decrease in filtration rate in a significant number of glomeruli will cause the connected tubules to become unsaturated, and glucose $T m$ will decrease by a corresponding amount (7). The application of glucose $T m$ in appraising glomerular activity will be discussed elsewhere; here we wish to report only the observed values under standard conditions.

The elevation of plasma glucose to the high levels involved in this measurement (350 to 700 mgm. per cent) may be expected to expand the plasma volume, under which conditions the renal blood flow might be modified either reflexly or through autonomous local adjustments. Evidence on this point will be presented separately; we need only note here that we do not consider the data on the diodrast clearance when obtained simultaneously with the measurement of glucose $T m$ as physiologically comparable with the other 
data on this clearance presented here. Consequently, the diodrast clearance has been omitted from Table III. We have no reason, however, to believe that either the inulin clearance or the value of diodrast $T m$ is altered in normal subjects under these conditions, and we consider these data (Table III) as physiologically homogeneous with those presented in Tables I and II and have accordingly included them in the statistical summary.

\section{THE QUESTION OF PHYSIOLOGICALLY ACCEPTABLE " STANDARD" VALUES OF THE DIO- DRAST CLEARANCE 5}

\section{Inulin, phenol red and diodrast}

The first point to be considered in this connection is the possibility of hyperemia induced by pyrogenic inulin. The presence of pyrogen in inulin and a method of removing the pyrogen were reported by Goldring and Smith in 1936 (5), and a more effective method of purification was re- ported by Smith, Chasis and Ranges in 1938 (11). In adequate doses this pyrogen can produce renal hyperemia (10). Ever since the hyperemic properties of this pyrogen were discovered, we have been aware of the danger of this action complicating our observations. That such has not been the case we are convinced for the following reasons: When pyrogenic inulin is given in even threshold doses, the first reaction is a rise in temperature two to four hours after administration, usually with complaints of chilliness and other subjective reactions. We have never succeeded in producing renal hyperemia by doses too small to produce the febrile reaction. When administered in larger doses, there has, in our experience, invariably been a latent period of at least ninety minutes before the development of renal hyperemia. Since 1936 rectal temperatures have been taken routinely on all subjects, both during observation and every hour therreafter until 4:00 p.m., and in all the data on diodrast clearance recorded here, the observations have been concluded within approximately sixty minutes after the first inulin injection. In no instance has the afternoon

s The question of quantitative correspondence between the plasma diodrast clearance and the actual renal plasma flow (or between the whole blood diodrast clearance and renal blood flow) will not be discussed here since it will be treated in a forthcoming publication. temperature exceeded $100^{\circ} \mathrm{F}$., nor have there been subjective evidences of pyrogenic reaction. Consequently, we set aside as improbable the possibility that our mean value for the diodrast clearance has been elevated by pyrogenic hyperemia.

With regard to diodrast, it is known that the rapid intravenous administration of relatively large doses of this substance cause a transitory fall in blood pressure (3), but the doses involved exceed many times the quantities which we use in clearance determinations. These quantities are typically $350 \mathrm{mgm}$. (1 cc.) as a priming dose, followed by infusion at the rate of $16 \mathrm{mgm}$. per minute. Smith, Goldring and Chasis (12) found that small doses of diodrast ( 0.35 to 1.5 grams) do not increase the phenol red clearance, and more recently we have made numerous observations in which the plasma concentration of diodrast has been slowly elevated from 1.0 to $10 \mathrm{mgm}$. per cent, without any increase in diodrast clearance. On the basis of this evidence we exclude the supposition that diodrast has produced renal hyperemia. ${ }^{\circ}$

With regard to phenol red, Herrick, Mann and Sheehan (6) have reported that injections of this substance increase the renal blood flow (thermostromuhr method) in unanesthetized dogs. The average dose used by these investigators was 15 cc. of a 6 per cent solution injected in one minute, or $900 \mathrm{mgm}$. per minute. In one of the two experiments illustrated by them the disturbance in renal blood flow had passed off in ten minutes, and in the other there was practically no change. In both experiments the dog vomited immediately after the injection. The largest quantity of phenol red we have used has been $30 \mathrm{mgm}$. per minute for ten minutes as a priming dose completed twenty minutes before the first clearance period, followed by infusion at $4 \mathrm{mgm}$. per min-

6 This applies only to the measurement of the diodrast clearance at low plasma levels of diodrast. Following the injection of 30 to $40 \mathrm{cc}$. of diodrast for the measurement of diodrast $T m$, there appear to be occasional disturbances in the renal blood flow, as indicated by a slight to moderate fall in the inulin clearance. The circulatory effects of these large doses cannot be examined by the diodrast clearance method, since the tubules are then saturated and the extraction ratio depressed. But any circulatory effects of large doses given relatively quickly would not controvert the evidence that small doses have no such effect. 
ute (12); assuming a $10 \mathrm{kgm}$. dog and $60 \mathrm{kgm}$. man, the dose given by Herrick, Mann and Sheehan is about 180 times our priming infusion, and 1350 times our maintenance infusion. In the absence of better evidence, we therefore discount the possibility of phenol red having induced renal hyperemia.

\section{PSYCHOGENIC DISTURBANCE, SELECTION, AND HYDRATION}

In brief, we believe that the chemical elements involved in clearance determinations have introduced no significant error in the data of Tables I and II. We are, however, aware of three factors which should be considered in presenting our data as "standard" normal values.

First, there is the factor of psychogenic disturbance. The mere procedures of catheterization, venipuncture, and the attendance of 3 or more persons are obvious sources of apprehension to some patients. The actuality of psychogenic vasoconstriction in the kidney has recently been demonstrated (10) and, though the question is not open to experimental investigation at the present time, we fully recognize the possibility that such apprehension as may unavoidably be associated with the procedure of clearance determination may produce renal vasomotor disturbance. Where our subjects have been examined on 2 or more occasions, the diodrast clearance has been larger in the second than in the first examination less than 50 per cent of the time (Tables I and II). Nevertheless, nearly all our data involve repeated observations on " trained" subjects, i.e., subjects who are quite accustomed to clearance examination, and this fact may have led to a figure for the mean diodrast clearance somewhat above the figures which have been reported by others $(2,17)$.

Secondly, we recognize the possibility that selection may have influenced our data. Many of our subjects have been selected with a view to the examination of pharmacologic agents, etc., and it may be that we have selected a group of subjects which, in respect to renal function, is not fairly representative of the general population. We wish merely to call attention to this possibility for we strongly discount its actuality.

The third factor bearing on this point is the degree of hydration of the subject. Our subjects take a liter of water the night before, and another liter on the morning of the examination (the last water at least ninety minutes before the first clearance period) and, although we have observed no difference in a few comparative observations on the same subjects, it may be that this thorough hydration results in an increased renal blood flow. But even if such is the case, we believe that a standard technique such as this is preferable to one which will permit variable dehydration to enter as a complication.?

In view of the above considerations, we present our data as "standard" rather than "basal" 8 observations, emphasizing that the conditions under which they have been made are both physiological and reproducible. The technique of making all such observations must be improved as knowledge of the renal circulation is increased.

\section{DISCUSSION}

The larger series of data presented in Table I requires no discussion other than to note that the average inulin and phenol red clearances compare favorably with the average values previously reported for 25 subjects (12). The present average diodrast clearance is substantially less than that previously reported, but the previous figure was based on only 6 subjects, 2 of whom were counted twice.

The most significant aspect of the present data is the quantitative relationship which exists between the diodrast clearance and the inulin clearance, on the one hand, and diodrast $T m$, on the other. Examination of the data on those subjects in whom diodrast $T m$ has been measured shows that this term has a close positive correlation with both clearances, as shown in Figures 1 and 2.

7 We recommend thorough hydration in order to maintain the urine flow and to permit accurate clearance periods. Where both hydration and $\mathrm{Na}_{2} \mathrm{SO}_{4}$ are contraindicated, 7 to 8 per cent mannitol or sorbitol (Abbott ampules) may be incorporated in the infusion as a diuretic. Dr. Catherine Welsh and her co-workers (personal communication) have used the hexitols for this purpose in clearance studies on normal pregnant women and women with pre-eclampsia.

8 The ambiguity of the term "basal" is illustrated by the recent studies of Scott, Bazett and MacKie (8) on the circulation under various climatic conditions. 
TABLE IV

Statistical analysis of subjects with diodrast Tm

(Men and women are treated as one series)

\begin{tabular}{|c|c|c|c|c|c|c|}
\hline - & $\begin{array}{c}\text { Number } \\
\text { of } \\
\text { subjects }\end{array}$ & - Range & Mean & 。 & $r$ & $\frac{\sigma}{\text { mean }}$ \\
\hline 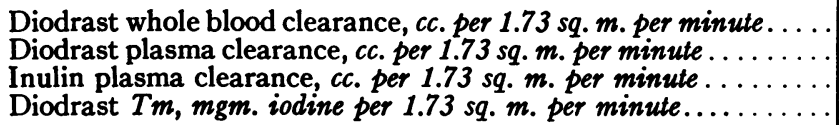 & $\begin{array}{l}28 \\
28 \\
35 \\
35\end{array}$ & $\begin{array}{l}718-1566 \\
455-921 \\
92-179 \\
36.6-72.0\end{array}$ & $\begin{array}{r}1115 \\
669 \\
131 \\
51.6\end{array}$ & $\begin{array}{r}219 \\
128 \\
22.1 \\
9.4\end{array}$ & & $\begin{array}{l}19.6 \\
19.1 \\
16.9 \\
18.2\end{array}$ \\
\hline$\frac{\text { Diodrast whole blood clearance }}{\text { Diodrast } T m}$. & 28 & $16.0-29.5$ & 22.3 & 2.70 & 0.77 & 12.1 \\
\hline$\frac{\text { Diodrast plasma clearance }}{\text { Diodrast } T m}$ & 28 & $10.2-16.7$ & 13.4 & 1.4 & 0.74 & 10.5 \\
\hline$\frac{\text { Inulin clearance }}{\text { Diodrast } T m}$. & 35 & $2.09-3.12$ & 2.56 & 0.28 & 0.77 & 9.0 \\
\hline
\end{tabular}

$$
\sigma=\sqrt{\frac{\Sigma(m-x)^{2}}{n}} \cdot r=\frac{\frac{\Sigma x y}{n}-m_{x} m_{y}}{\sigma_{x} \sigma_{y}} \cdot \sigma_{m}=\frac{\sigma}{\sqrt{n}}
$$

The value of $r$ in column 6 refers to the correlation between the numerator and denominator.

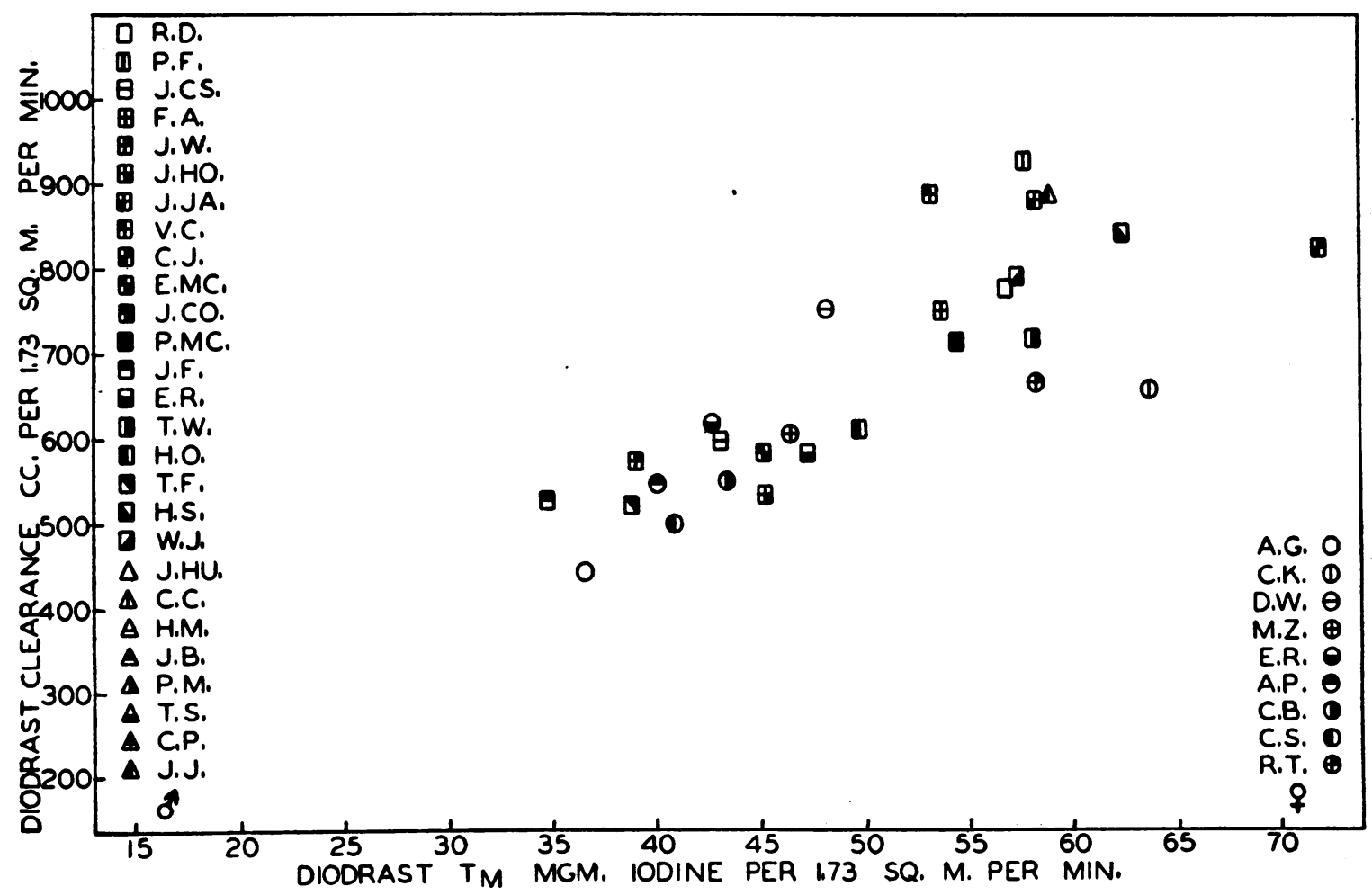

Fig. 1. The Plasma Diodrast Clearance (Effective Renal Plasma Flow) in 28 Subjects (Men and Women) in Relation to Diodrast Tm (Tubular Excretory Mass), as Recorded in Tables I and II

Each subject enters once only into the calculation of the correlation coefficient (0.77). Diodrast $T m$ may be taken as proportional to the total functional tubular tissue, and therefore closely proportional to the kidney weight. 


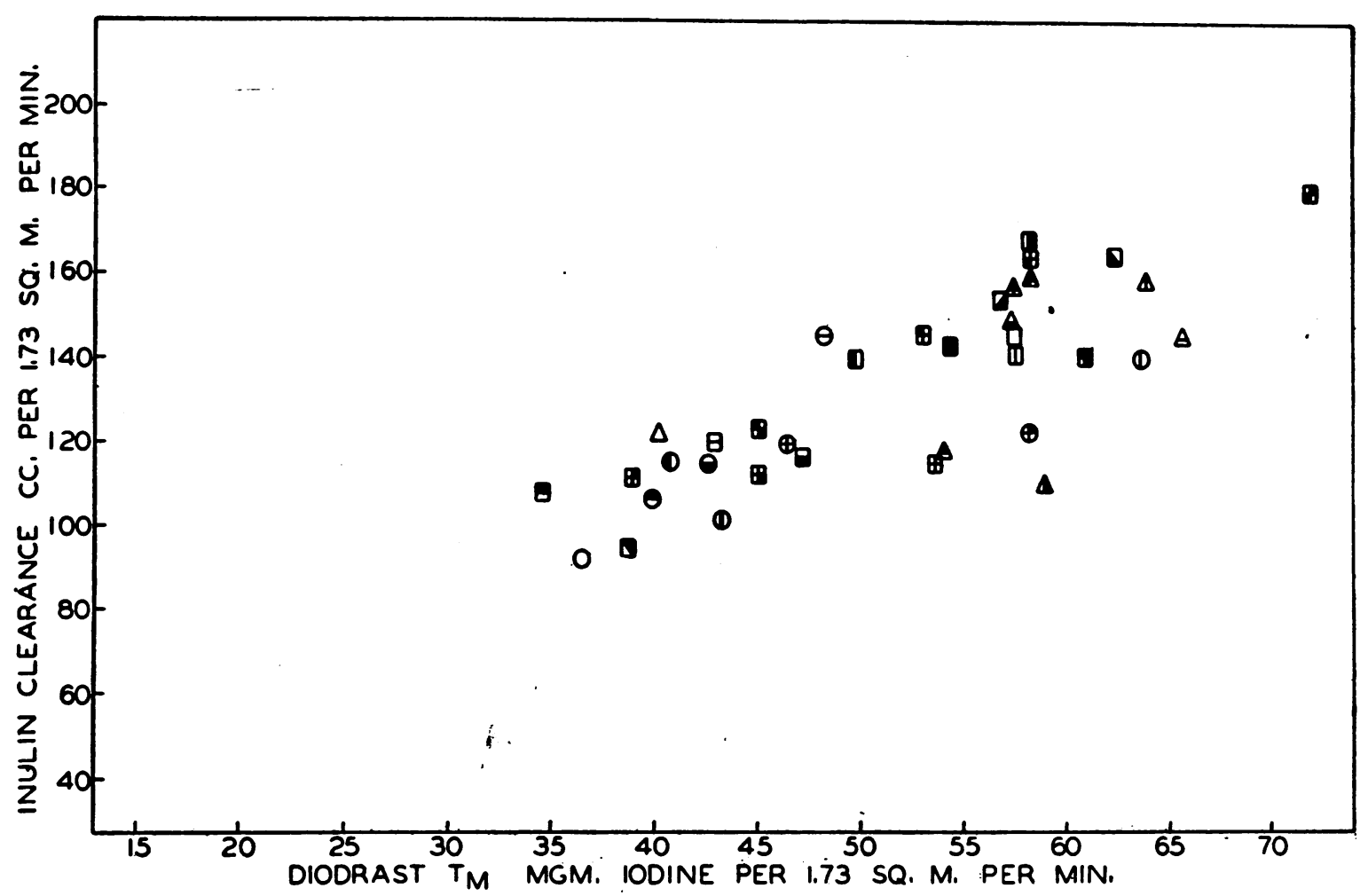

Fig. 2. The Plasma Inulin Clearance (Filtration Rate) in 35 Subjects (Men and Women) in Relation to Diodast Tm (Tubular Excretory Mass), as Recorded in Tables I, II, and III

The correlation coefficient is 0.77 .

In Table IV we have calculated the coefficient of correlation between diodrast $T m$ and the whole blood diodrast clearance, the plasma diodrast clearance and the inulin clearance. There are also presented in this table the standard deviations for these clearances, calculated on the same subjects. (Each subject is here considered once only. Data are available on 35 subjects for the inulin clearance, but on only 28 subjects for diodrast clearances since on 7 subjects diodrast $T m$ was determined simultaneously with glucose $T m$, under which conditions, as we have pointed out above, the diodrast clearances are physiologically suspect.)

Reference to Table IV shows that the standard deviation expressed in per cent of the mean is substantially smaller when the clearances are related to diodrast $T m$ than when they are considered independently. We interpret this fact to indicate that differences in the clearances are in part attributable to such differences in the size of the kidneys as are not excluded by the usual correc- tion for body surface area, these differences in kidney size being evident in data on normal kidney weights (16). To what extent diodrast $T m$ is strictly proportional to kidney weight is at present unknown, but since diodrast $T m$ is in theory a measure of the total quantity of tubular excretory tissue in the kidney, we would expect the correlation between these two terms to be of a significantly high order. In this view, diodrast $T m$ may be taken as a measurement of kidney size, and from the close correlations shown in Table IV and Figures 1 and 2, we would be permitted to say that the whole blood or plasma diodrast clearance and the inulin clearance in various individuals are relatively more constant when compared per unit of kidney weight than when compared per sq. $\mathrm{m}$. of body surface area.

The present series of data on glucose $T m$ is too small to afford an accurate statistical analysis. The average glucose $T m$ /diodrast $T m$ ratio in 10 subjects is 6.49 .

Relative to the data in Table IV, it should be 
noted that according to statistical theory it is impossible to define the absolute range of " normal" values. Statistical analysis at best affords a statement of the probabilities that a given observation belongs to the population which has been analyzed. If in this population there is a symmetrical distribution of the individuals about the mean, then 95 per cent of the individuals will fall within $m \pm 2 \sigma$, and 99.5 per cent within $3 \sigma$. Or, conversely, there is one chance in 20 that an individual actually belonging to this population may fall outside the range of $\pm 2 \sigma$, and one chance in 200 that it may fall outside the range of $\pm 3 \sigma$. If, for example, a particular diodrast clearance falls just below 413 or just above $925( \pm 2 \sigma)$, there is still one chance in 200 that it is " normal" with respect to the data of Table IV. The absolute identification of this subject as having abnormal renal function is statistically impossible.

Thirty-five subjects is, moreover, so small a statistical series that it affords a fair chance of sampling error. We would, at the present time, place more emphasis upon the physiological sources of variation discussed above than upon the statistical significance of this limited series.

We can briefly record here that we have utilized the ballistocardiographic method of Starr, et al. (15) for the measurement of cardiac output before and during the clearance determination in 6 subjects (12 observations). In no case have we found an increase in cardiac output, as referred to a control measurement on the morning of observation, to be associated with the clearance procedure (infusion, catheterization, etc.). This investigation is being extended by other methods of measuring cardiac output in order to confirm the accuracy of the ballistocardiographic method in our hands.

\section{SUM MARY}

Data on the diodrast and inulin clearances, and on the maximal rate of tubular excretion of diodrast (diodrast $T m$ ) and the maximal rate of tubular reabsorption of glucose (glucose $T m$ ) are presented for a series of normal men and women.

Diodrast $T m$, a measure of the total quantity of tubular excretory tissue in the kidney, is conceived to be roughly proportional to the total quantity of renal parenchyma.
Statistical analysis of the data reveals that both the diodrast and inulin clearances increase in proportion to diodrast $T m$, and that comparison of clearances in different individuals is more accurate when made on the basis of diodrast $T m$ than when the absolute values of the clearances are considered alone. This method of comparison is functionally equivalent to expressing the renal plasma or whole blood flow and the filtration rate on the basis of unit mass of renal parenchyma.

The significance of the mean values of the diodrast clearance, etc., is discussed in relation to the possible perturbation of renal blood flow by factors involved in the clearance procedure, such as inulin and diodrast, and by selection of subjects, hydration and psychic influences. It is believed that the data accurately reflect the renal blood flow under "standard" conditions which closely approach the ordinarily accepted concept of basal conditions in the systemic and renal circulation.

The authors are indebted for unfailing cooperation to Dr. Willie W. Smith, Katharine S. Tilson, Helen A. Keigher, Anna Rosenthal, Norma Finkelstein, Frances E. Marx, Anna M. Lublin, Betty J. Crawford, Martha J. Barrett and Lucy M. Aliminosa, who have at one time or another participated as analysts in this investigation; to Barbara A. Parker and Mr. Sylvan M. Stillman, who have assisted in the measurement of the ballistocardiographic records; and to Nurse Ann S. Rivoire.

\section{METHODS}

Only important changes from methods previously described (12) are detailed below :

1. Infusion fluid. This is prepared in 0.9 per cent saline (Sterisol saline, Schering and Glatz, Inc.) and administered from an open infusion flask without precautions for maintaining temperature, the rate being timed by means of a Murphy drip chamber and regulated by means of a 4-inch tunnel clamp. Typical protocols follow :

Diodrast clearance. To $800 \mathrm{cc}$. of saline are added 12 cc. of 35 per cent diodrast solution (Winthrop Chemical Company) and $25 \mathrm{cc}$. of 10 per cent inulin solution (U. S. Standard Products Company). Immediately after the infusion is started (zero minutes), $1.3 \mathrm{cc}$. of diodrast solution and $15 \mathrm{cc}$. of inulin solution are injected into the infusion tubing as a priming dose. (A control blood sample $\left(B_{0}\right)$ is drawn when venipuncture is first made.) $U_{0}$ is collected at $20^{\prime}, B_{1}$ at $22^{\prime}, U_{1}$ at $32^{\prime}, U_{2}$ at $44^{\prime}, U_{2}$ at $56^{\prime}$, and $B_{2}$ at $54^{\prime}$ or $58^{\prime}$.

Diodrast $T m$. The infusion tubing is disconnected from the needle, the infusion fluid drained to $400 \mathrm{cc}$; $11.5 \mathrm{cc}$. of diodrast are added to each $100 \mathrm{cc}$. of infusion 
left in the flask and mixed, and 26 cc. of diodrast are injected into the infusion tubing as a priming dose. The infusion is accelerated for a short time to empty the dead space of dilute diodrast, the rate then being restored to 4 cc. per minute. Twenty minutes later (ca. $79^{\prime}$ ), $U_{\infty}$ (second discard) is collected, $B_{3}$ is drawn at $81^{\prime}, U_{4}$ at $91^{\prime}, U_{6}$ at $103^{\prime}, B_{4}$ at $113^{\prime}, U_{6}$ at $115^{\prime}, U_{7}$ at $127^{\prime}, U_{8}$ at $139^{\prime}$, and $B_{5}$ at $137^{\prime}$ or $139^{\prime}$.

In the average normal subject the above infusion will give $10 \mathrm{mgm}$. per cent of inulin in the plasma, $1.5 \mathrm{mgm}$. per cent of diodrast iodine between $B_{1}$ and $B_{2}$ and 30 . mgm. per cent between $B_{3}$ and $B_{5}$. If the clearances are approximately known, the appropriate quantities of inulin and diodrast can be related to the desired plasma iodine concentration in $\mathrm{mgm}$. per cent $\left(P_{D}\right)$ and body weight ( $(\mathrm{kgm}$.) on the basis that the priming dose is distributed in approximately 20 per cent of the body weight, and that at a constant rate of infusion, this rate will equal UV. That is, the priming injection in cc. should equal $\frac{P_{D} \mathrm{kgm} \text {. }}{70}$ cc., and $\frac{P_{D} C_{D}}{700}$ cc. of 35 per cent diodrast solution should be added to each $100 \mathrm{cc}$. of infusion. For $T m_{D}$, the priming injection is calculated in the same manner and the sustaining infusion should contain $\frac{T m_{D}+P_{D} .02 T m_{D}}{70}$ cc. of diodrast solution, since $U V$ $=T m_{D}+P_{D} F W 2.57 T m_{D} / 100$. With 10 per cent inulin solution the priming dose should be $\frac{P_{I N} \mathrm{kgm}}{40} \mathrm{cc}$. and each $100 \mathrm{cc}$. of infusion should contain $\frac{P_{I N} C_{I N}}{400} \mathrm{cc}$.

Glucose $T m$. Glucose (50 per cent solution) to the extent of 18 per cent is incorporated in the infusion fluid and 25 grams of glucose are injected into the infusion tubing as a priming dose, and $\mathbf{2 5}$ grams of glucose (pure) are given per os at zero minutes and again about midway in the observations. Depending on glucose $T m$, this yields 350 to $750 \mathrm{mgm}$. per cent glucose in arterial blood. If the hand is warmed in hot water, the venous blood from the veins of the hand or wrist may be used instead of arterial blood, there being no $A-V$ difference at this level of hyperglycemia and constant blood glucose level. The blood glucose level should be constant or rising for this measurement. It has been our experience that subjects showed marked differences in capacity to store and utilize glucose. Since glucose storage and utilization seem usually to be accelerated after the administration of a glucose infusion for an hour or so, it is most difficult to maintain the requisite plasma level of glucose during the second hour.

2. Analytical methods. We have recently adopted the inulin method of Alving, Rubin and Miller (1), with the modification recommended by them (personal communication). It has been our experience that pure diphenylamine is necessary in this method. We have found the material supplied by Pfanstiehl Chemical Company and the G. Frederick Smith Chemical Company to be satisfactory. In order to conserve blood we have changed the technique slightly from the original description:
Glucose is removed from blood and urine by treatment with a yeast suspension which has been well washed (6 to 8 times). This suspension will keep for a week or longer in the icebox, but must be centrifuged and freshly suspended on the day of use. Two cc. of plasma are mixed with $6 \mathrm{cc}$. of $\mathrm{ca}$. 20 per cent yeast suspension (of known hematocrit) in $16 \times 125 \mathrm{~mm}$. pyrex fubes. The mixture is occasionally agitated, and centrifuged after fifteen minutes at room temperature. From 2 to 5 cc. (typically $2 \mathrm{cc}$.) of the supernatant fluid are removed to a 50-cc. Erlenmeyer flask containing $5 \mathrm{cc}$. of water and $6 \mathrm{cc}$. of $\mathrm{ZnSO}_{4}-\mathrm{H}_{2} \mathrm{SO}_{4}$ mixture prepared as described by Somogyi (14). This mixture is well agitated and 2 cc. of $0.75 \mathrm{~N} \mathrm{NaOH}$ are added. The flask is closed with the finger and well shaken. The mixture is centrifuged in $20 \times 150 \mathrm{~mm}$. heavy-walled pyrex tubes and filtered through a pledget of washed cotton. The total dilution should yield about $0.50 \mathrm{mgm}$. per cent of inulin in the filtrate. Five cc. of the above filtrate are transferred in duplicate to the special tube recommended by Alving, et al., and the inulin determination carried out with the diphenylamine reagent according to their specifications. Color is read in an Evelyn colorimeter, using a 635 filter. The urine samples, after dilution to a $U / P$ ratio of approximately 1.0, are yeasted, precipitated and analyzed in the same manner as the plasma.

For the determination of the yeast plus plasma inulinoid blank, 2 cc. of plasma from $B_{0}$ plus $2 \mathrm{cc}$. of $5 \mathrm{mgm}$. per cent inulin are treated with $6 \mathrm{cc}$. of yeast, and $3 \mathrm{cc}$. are precipitated as above. This blank varies from 0.1 to 0.7 , and usually falls in the lower range of these figures. Duplicate inulin standards containing $0.2,0.5$ and 0.8 mgm. per cent, as well as triplicate reagent blanks are included. Apart from preparing washed yeast and washing apparatus, one analyst, when using an 8-tube, I. E. C. centrifuge, can complete duplicate determinations on 5 plasma and 8 urine samples, with one $B_{0}$ sample, in eight hours.

Glucose in plasma and urine is analyzed by the Folin (4) method, using the technique of a single standard as described by Smith, et al. (12).

Iodine is analyzed by the Kendall method as modified by Smith, et al. (12), except that $3 \mathrm{cc}$. instead of $5 \mathrm{cc}$. of plasma are now used for low plasma iodine levels (1 to $2 \mathrm{mgm}$. per cent). Two cc. of plasma are used for high plasma iodine levels. An automatic filling 2-cc. burette, graduated in 0.01 cc. (E. Machlett and Sons, New York) placed in a well-lighted cabinet with white interior, has been found extremely useful for titration. Six plasma and 12 urine samples can easily be analyzed in duplicate in eight hours by one analyst. This method has repeatedly been demonstrated to give 100 per cent recovery of added iodine in organic form and yields very satisfactory checks. The chief difficulty encountered in its use has been in the growth of mold on the inner walls of the 5-gallon bottles which we commonly use for distilled water. This mold becomes detached and catalyzes the oxidation of $\mathrm{KI}$ to $\mathrm{I}_{2}$. The difficulty has been cir- 
cumvented by washing the bottles with cleaning fluid once every week or so.

For the determination of phenol red, 2 cc. of plasma are added to an S-tube (Evelyn colorimeter) containing 10 cc. of 0.9 per cent $\mathrm{NaCl}$. While following the optical transmission on the galvanometer ( 540 filter), the mixture is acidified with 5 per cent acetic acid ( 3 to 5 drops) until maximal transmission is obtained (just short of precipitation of proteins) and used to set the galvanometer at 100. Two drops of saturated $\mathrm{Na}_{2} \mathrm{CO}_{2}$ are then added, the contents of the tube mixed, and the transmission read on the galvanometer scale. The phenol red content is determined from a standard curve prepared in this manner with plasma and known concentrations of phenol red.

\section{BIBLIOGRAPHY}

1. Alving, A. S., Rubin, J., and Miller, B. F., A direct colorimetric method for the determination of inulin in blood and urine. J. Biol. Chem., 1939, 127, 609.

2. Chesley, L. C., and Chesley, E. R., The diodrast clearance and renal blood flow in normal pregnant and non-pregnant women. Am. J. Physiol., 1939, 127, 731.

3. Edwards, E. A., and Biguria, F., A comparison of skiodan and diodrast as vasographic media, with special reference to their effect on blood pressure. New England J. Med., 1934, 211, 589.

4. Folin, O., Two revised copper methods for blood sugar determinations. J. Biol. Chem., 1929, 82, 83.

5. Goldring, W., and Smith, H. W., Inulin and its suitability for intravenous administration in man. Proc. Soc. Exper. Biol. \& Med., 1936, 34, 67.

6. Herrick, J. F., Mann, F. C., and Sheehan, H. L., The influence of phenol red and creatinine on the renal blood flow. J. Pharmacol. \& Exper. Therap., $1939,66,73$.
7. Ranges, H. A., Chasis, H., Goldring, W., and Smith, H. W., The functional measurement of the number of active glomeruli and tubules in the kidneys of normal and hypertensive subjects. Am. J. Physiol. (Proc.), 1939, 126, 603.

8. Scott, J. C., Bazett, H. C., and MacKie, G. C., Climatic effects on cardiac output and the circulation in man. Am. J. Physiol., 1940, 129, 102.

9. Shannon, J. A., and Fisher, S., The renal tubular reabsorption of glucose in the normal dog. Am. J. Physiol., 1938, 122, 765.

10. Smith, H. W., The physiology of the renal circulation. Harvey Lect., 1939-40. (In press.)

11. Smith, H. W., Chasis, H., and Ranges, H. A., Suitability of inulin for intravenous administration to man. Proc. Soc. Exper. Biol. \& Med., 1938, 37, 726.

12. Smith, H. W., Goldring, W., and Chasis, H., The measurement of the tubular excretory mass, effective blood flow and filtration rate in the normal human kidney. J. Clin. Invest., 1938, 17, 263.

13. Smith, W. W., and Smith, H. W., Protein binding of phenol red, diodrast, and other substances in plasma. J. Biol. Chem., 1938, 124, 107.

14. Somogyi, M., A method for the preparation of blood filtrates for the determination of sugar. J. Biol. Chem., 1930, 86, 655.

15. Starr, I., Rawson, A. J., Schroeder, H. A., and Joseph, N. R., Studies on the estimation of cardiac output in man, and of abnormalities in cardiac function, from the heart's recoil and the blood's impacts; the ballistocardiogram. Am. J. Physiol., 1939, 127, 1.

16. Wald, $H$., The weight of normal adult human kidneys and its variability. Arch. Path., 1937, 23, 493.

17. White, H. L., Findlay, T., Jr., and Edwards, J. C., Interpretation of diodrast clearances in man. Proc. Soc. Exper. Biol. \& Med., 1940, 43, 11. 